\title{
PENGGUNAAN COMPUTED RADIOGRAPHY UNTUK IDENTIFIKASI MADU LEBAH
}

\author{
Sri Maiyena \\ Jurusan Pendidikan Fisika FTIK IAIN Batusangkar \\ Jalan Sudirman No. 137 Kubu Rajo Lima Kaum Batusangkar. \\ Email: Sri_Maiyena@yahoo.com
}

\begin{abstract}
Research on identification of honey bee using Computed Radiography has been done. The testing was carried out by providing digital radiograph of the three types of honey bee. The voltage of the x-ray generator was varied at $50 \mathrm{kV}, 60 \mathrm{kV}$ and $70 \mathrm{kV}$, while filament current was set at 100 $\mathrm{mA}$ and exposure time was at $5 \mathrm{~ms}$. Honey bee was identified based on the image line profile that indicated the distribution of linear absorption coefficient $(\mu)$ for each sample. The analyses on the image line profile showed that at the voltage of $50 \mathrm{kV}$ and $70 \mathrm{kV}$ the three kinds of the honey bee can be distinguished. However, at the voltage of $60 \mathrm{kV}$ the difference among honey bee was unable to be identified.
\end{abstract}

Key words: Computed Radiografi, honey bee, linier absorption coefficient

\section{PENDAHULUAN}

Madu murni merupakan cairan nektar bunga yang dihisap oleh lebah madu ke dalam kantong madu di dalam tubuhnya (Adriani, 2011). Madu palsu atau tiruan adalah larutan yang menyerupai madu. Madu palsu ini dibuat tanpa pertolongan lebah atau menggunakan gula sebagai nektar. Umumnya madu palsu ini mempunyai warna sama dengan madu asli. Oleh karena itu bagi orang awam sulit untuk membedakan antara madu asli dan madu tiruan. Madu palsu dibuat dengan suatu rekayasa sehingga memiliki sifat, rasa dan aroma yang sangat mirip dengan madu asli (Maun, 1999). Oleh karena itu kita harus memiliki pengetahuan untuk membedakan madu alami dan palsu.

Pengujian kadar keaslian madu memang tidak gampang, disamping biayanya juga mahal. Dibutuhkan alat-alat canggih untuk mendeteksi ada tidaknya campuran dengan gula lainnya didalam madu. Kandungan madu murni sangat beraneka ragam tergantung dari sumber nektar dimana lebah memperolehnya. Namun, darimanapun nektarnya madu murni merupakan sumber gizi yang sangat lengkap (Suranto, 2007).

Dimasyarakat berkembang kebiasaan uji keaslian madu yang ditunjukkan menyala ketika dibakar dengan korek api, telur bisa matang, tidak rembes ketika diteteskan pada kertas koran, dan sebagainya. Pengujian tersebut sebenarnya tidak seratus persen benar, masih butuh pembuktian melalui laboratorium. Salah satu pengujian yang bersifat tidak merusak adalah dengan menggunakan computed radiography.

Penggunaan teknik computed radiography ini diharapkan dapat mengidentifikasi karakteristik madu lebah berdasarkan profil garis yang mencerminkan koefisien serapan liniernya. Penggunaan teknik radiografi ini telah digunakan oleh beberapa peneliti sebelumnya, seperti inspeksi keramik dengan radiografi sinar-X (Cahyono, 2003), inspeksi pipa berbasis radiografi sinar-x digital (Pasolang, 2003), inspeksi kandungan logam 
dalam cat dengan menggunakan teknik computed radiography (Fidiani, 2008), interpretasi radiograf digital pada industri pengelasan pipa (Setiawan, 2002). Penelitian lainnya juga dilakukan terhadap perbandingan kualitas citra computed radiografi dengan citra hasil digitisasi film radiograf (Wahyunengsih, 2009). Di samping itu juga telah dilakukan penelitian dalam menentukan kuantitas bahan material dan bahan aktif dari obat dengan menggunakan sinar-x (Bessler, 2008).

\section{METODE PENELITIAN}

Penelitian dilakukan di ruang roentgen Computed Radiography (CR) bagian Radiologi Rumah Sakit Stroke Nasional Bukittinggi. Penelitian berlangsung selama kurang lebih 2 bulan, yaitu pada bulan April sampai dengan Mei 2013. Pada penelitian ini menggunakan bahan madu lebah I (M1), madu lebah II (M2), madu lebah III (M3), sukrosa. Madu Lebah I merupakan sampel madu lebah dengan komposisi baik, sehingga dalam penelitian ini digunakan sebagai objek referensi. Sedangkan madu lebah II dan III merupakan objek yang diuji. Larutan gula merupakan bahan campuran dari madu lebah yang digunakan sebagai pembanding terhadap M1, M2 dan M3.

Analisis data terdiri atas tiga bagian yaitu analisis visual citra, analisis kualitas citra dan analisis fisis citra. Pada analisis visual citra dianalis terhadap image radiograf yang diperoleh menggunakan computed radiography. Analisis kualitas citra digital yaitu analisis profil garis dengan menggunakan program New Image Analyzer 2007. Melalui analisis profil garis dapat diperoleh informasi mengenai distribusi derajat keabuan dalam setiap posisi piksel dan diperoleh juga informasi mengenai ketajaman citra. Analisis fisis citra dilakukan dengan cara menghitung nilai koefisien serapan linear $(\mu)$ dari masing-masing citra sampel dengan menggunakan program New Image Analyzer 2007. Nilai $\mu$ hasil eksperimen selanjutnya dibandingkan dengan nilai $\mu$ hasil simulasi program XCOM.

\section{HASIL DAN PEMBAHASAN}

Hasil dan Analisis Citra Radiography Secara Visual

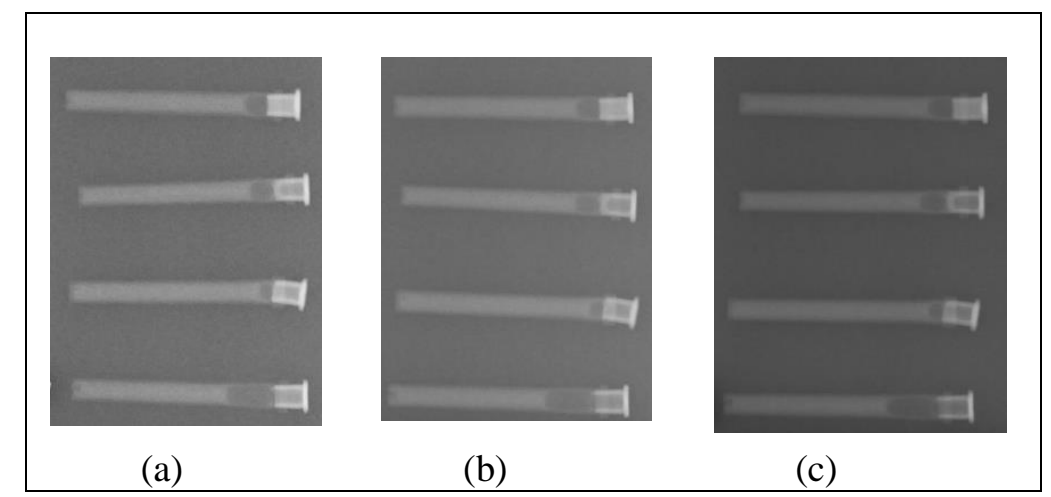

Gambar 1. Citra Computed Radiography pada tegangan (a) $50 \mathrm{kV}$ (b) $60 \mathrm{kV}$ (c) $70 \mathrm{kV}$

Secara visual hasil citra CR dapat dilihat pada Gambar 1 yang menunjukkan berbagai citra dengan variasi tegangan dengan kuat arus tetap $100 \mathrm{~mA}$ dan waktu paparan $5 \mathrm{~ms}$. Secara keseluruhan, ketiga citra tampak berbeda dalam hal kecerahan (brightness), kontras (contrast) dan ketajaman citra (sharpeness). Ini menunjukkan bahwa secara visual variasi tegangan mempengaruhi citra yang dihasilkan oleh CR. 
Pada citra gambar 1 (a), ke-4 objek yang digunakan tampak jelas. Kecerahan, kontras dan ketajaman citra terlihat sangat baik. Kecerahan citra tinggi, terlihat dari intensitas cahaya rata-rata dari objek tersebut. Ketajaman pun tinggi, terlihat dari batas-batas pada detail objek kasar maupun halus dan juga dari batas tepi objek yang terdeteksi dengan jelas. Kontras citra tampak baik karena gambar objek bisa terbedakan dengan backgroundnya. Secara visual terlihat bahwa ke empat objek yang diidentifikasi memiliki serapan radiasi yang hampir sama pada masing-masing variasi tegangan yang digunakan.

Secara visual hasil citra $\mathrm{CR}$ pada tegangan $50 \mathrm{kV}$ (Gambar 1.a) dan tegangan 60 $\mathrm{kV}$ (gambar 1.b) terlihat memiliki kecerahan yang hampir sama dibandingkan hasil citra CR pada tegangan $70 \mathrm{kV}$. Kecerahan, kontras dan ketajaman citranya tidak setajam pada citra menggunakan tegangan $50 \mathrm{kV}$. Pada tegangan $60 \mathrm{kV}$ dan $70 \mathrm{kV}$ terlihat bahwa ada beberapa objek dimana batas tepi objek terdeteksi kurang jelas. Kontras citra juga tidak sebaik hasil pada citra menggunakan tegangan $50 \mathrm{kV}$. Pada citra Gambar 1 (c) terlihat hampir sama dengan citra Gambar 1 (b). Kecerahan dan ketajaman citra terlihat hampir sama. Namun untuk kontras citra tampak lebih baik dibandingkan hasil citra menggunakan tegangan $60 \mathrm{kV}$.

Analisis secara visual, jika citra Gambar 1 (a) dibandingkan dengan citra Gambar 1 (b) dan citra gambar 1 (c) tampak sedikit perbedaan kecerahan, kontras dan ketajaman citra. Namun perbedaan tersebut tidak terlalu signifikan bila dianalisis secara visual sehingga dibutuhkan analisisyang lebih lanjut, yaitu analisis profil garis dan analisis fisis citra melalui penentuan koefisien serapannya secara kuantitatif.

\section{Profil Garis Citra}

Penentuan profil garis dari hasil citra computed radiography dianalisis menggunakan program New Image Analyzer 2007. Penggunanan program new image analyzer adalah untuk menentukan nilai graylevel terhadap posisi piksel citra. Hasil analisis tersimpan dalam format *.txt, dan kemudian di baca dengan menggunakan ms. excel.

Nilai graylevel rata-rata yang diperoleh, selanjutnya dibuatkan grafik profil garis citranya dengan menggunakan program Matlab 2007. Grafik profil nilai graylevel terhadap posisi piksel untuk tegangan $50 \mathrm{kV}, 60 \mathrm{kV}$ dan $70 \mathrm{kV}$ ditunjukkan pada Gambar 2, 3 dan 4.

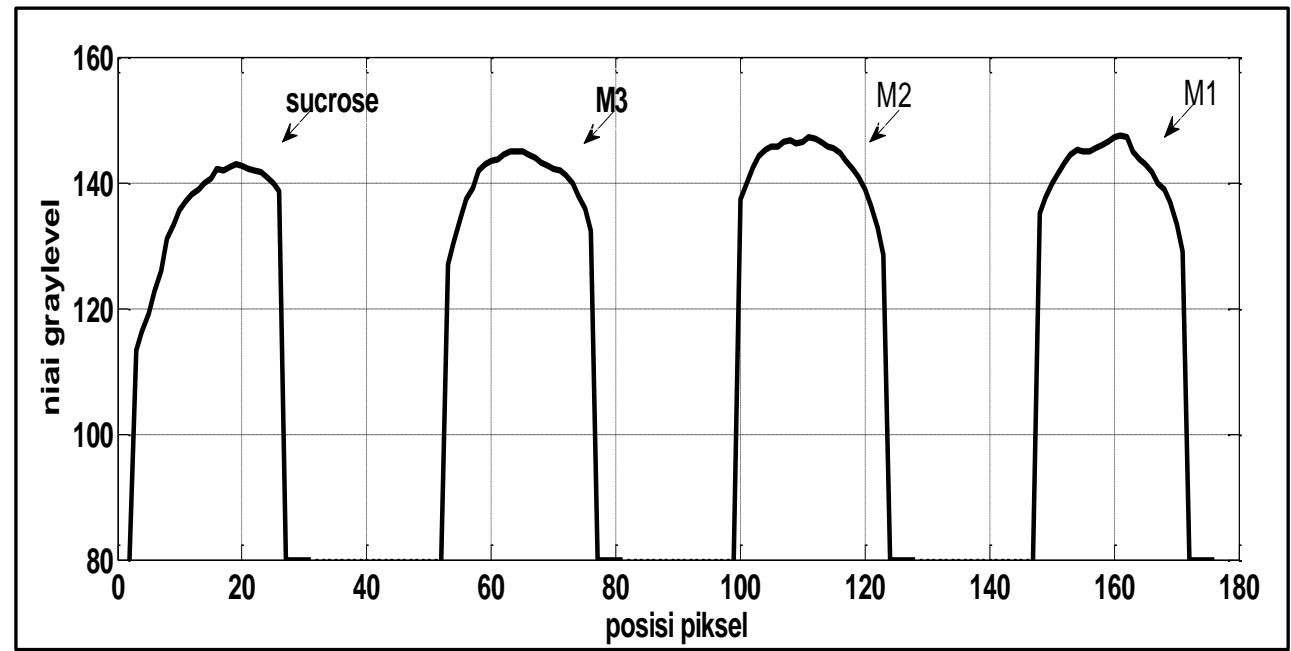

Gambar 2 Grafik profil garis fungsi nilai graylevel vs posisi piksel pada tegangan $50 \mathrm{kV}$ 
Grafik profil garis memberikan hasil secara kualitatif. Dari grafik profil garis pada $\mathrm{kV} 50$, terlihat bahwa dari ketiga bahan madu lebah yang diidentifikasi M1 memiliki koefisien serapan yang sama dengan M2, akan tetapi koefisien serapan M3 lebih kecil dibanding koefisien serapan M1 dan M2. Sukrosa terlihat memiliki koefisien serapan yang hampir sama dengan M3.

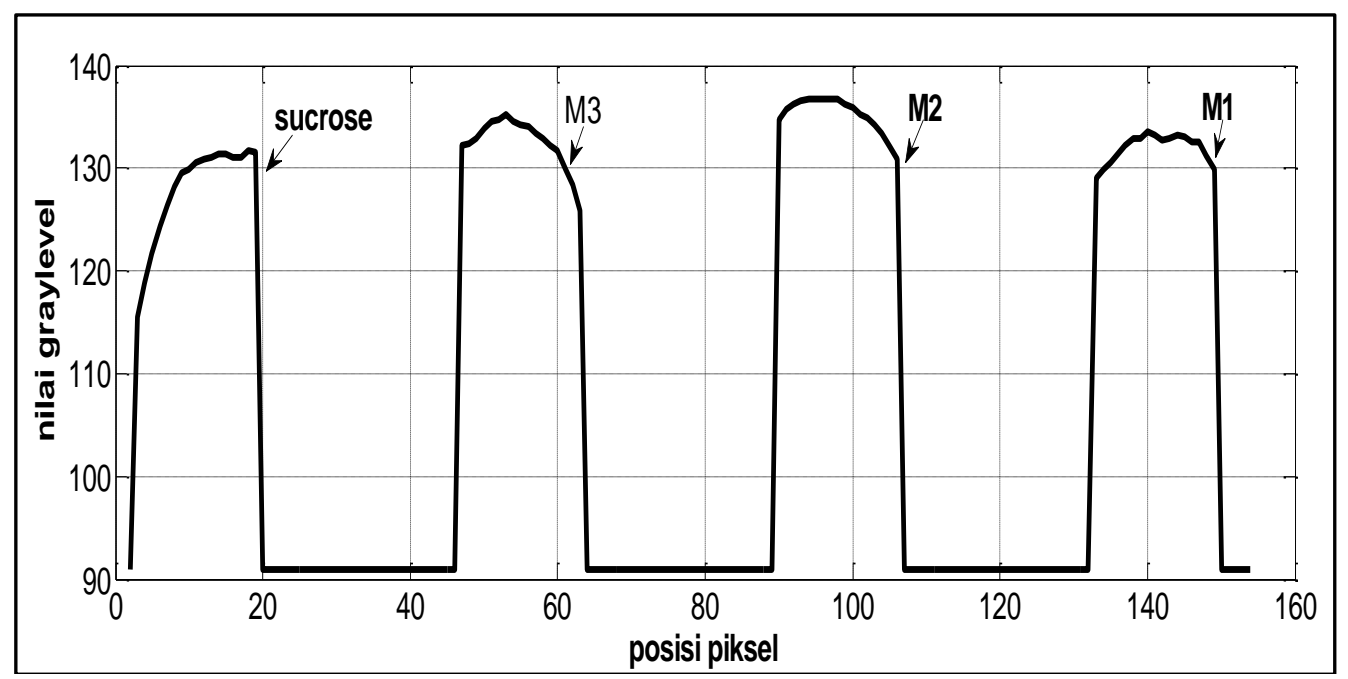

Gambar 3 Grafik profil garis fungsi graylevel vs posisi piksel pada tegangan $60 \mathrm{kV}$

Penggunaan tegangan $\mathrm{kV} 60$, terlihat bahwa M2 memiliki koefisien serapan yang lebih besar dibanding M3 dan M1. Koefisien

serapan M1 terlihat hampir sama dengan sukrosa.

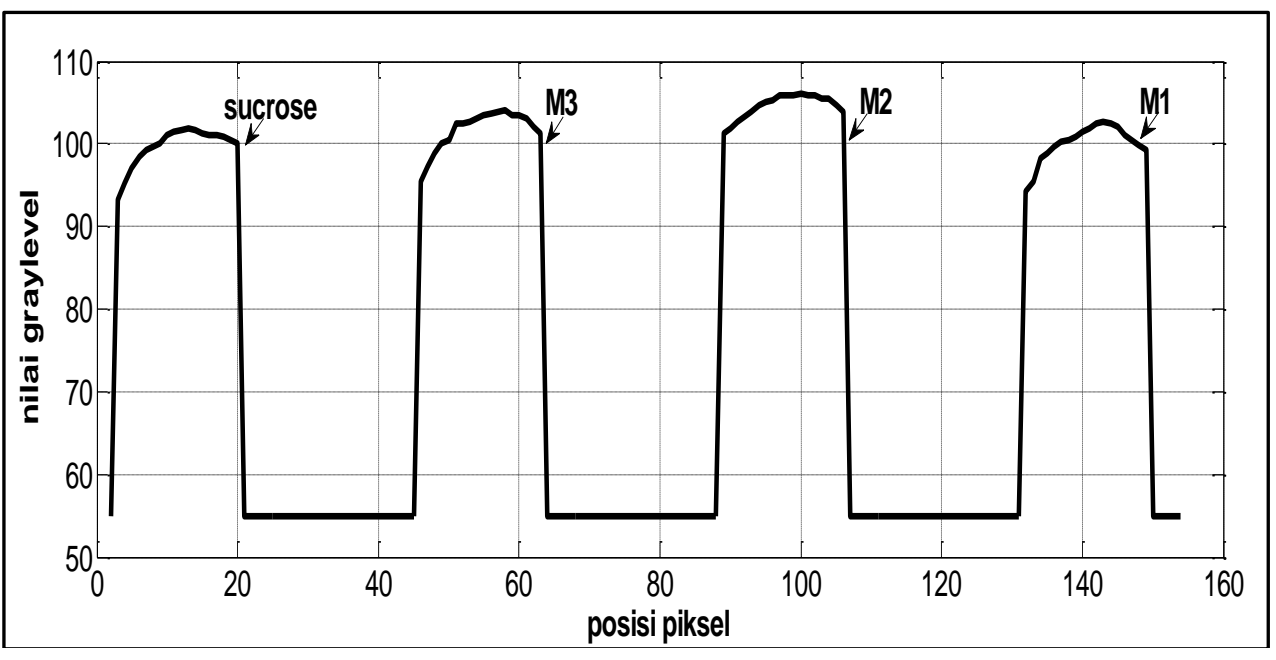

Gambar 4 Grafik profil garis fungsi graylevel vs posisi piksel pada tegangan $70 \mathrm{kV}$ 
Pada tegangan $70 \mathrm{kV}$, terlihat bahwa $\mathrm{m} 2$ memiliki koefisien serapan yang lebih besar disbanding M3 dan M1. Sedangkan sukrosa memiliki koefisien serapan hampir sama dengan M1.

Dalam hal ini grafik profil garis menunjukkan nilai koefisien serapan secara kualitatif. Secara umum pola profil garis dari madu lebah (M2 dan M3) dan bahan campurannya (sukrosa) hampir sama, baik pada tegangan $50 \mathrm{kV}, 60 \mathrm{kV}$ maupun $70 \mathrm{kV}$. Pola profil garis pada M1 pada tegangan $50 \mathrm{kV}$ berbeda dengan pola profil garis pada tegangan $60 \mathrm{kV}$ dan $70 \mathrm{kV}$. Dari ketiga variasi tegangan yang digunakan, terlihat bahwa madu lebah dan campurannya dapat diidentifikasi dengan menggunakan computed radiography pada tegangan $60 \mathrm{kV}$ dan $70 \mathrm{kV}$. Hal ini ditunjukkan dari nilai graylevelnya, dimana besar dan kecilnya nilai graylevel menunjukkan koefisien serapannya.

\section{Koefisien Serapan Linier}

Berdasarkan persamaan Beer-Lambert, nilai koefisien atenuasi linear merupakan gradient dari grafik fungsi $\ln \left(\mathrm{I}_{\mathrm{o}} / \mathrm{I}_{\mathrm{t}}\right)$ vs tebal bahan (x). Oleh karena itu grafik pada gambar 5,6 dan 7 dikonversi dulu menjadi grafik fungsi $\ln \left(\mathrm{I}_{\mathrm{o}} / \mathrm{I}_{\mathrm{t}}\right)$ vs tebal bahan $(\mathrm{x})$. Ketebalan bahan $(\mathrm{x})$ diperoleh dari pengkonversian posisi piksel citra.

Grafik hubungan antara $\ln \left(\mathrm{I}_{\mathrm{o}} / \mathrm{I}_{\mathrm{t}}\right)$ terhadap tebal bahan (x) untuk citra computed radiography di tampilkan pada gambar 5,6 dan 7 dengan variasi tegangan $50 \mathrm{kV}, 60 \mathrm{kV}$ dan 70 $\mathrm{kV}$.

Dari Gambar 5, 6 dan 7 dapat memberikan informasi koefisien serapan linear pada kedelapan objek yang diidentifikasi. Hasil perhitungan koefisien serapnya disajikan dalam Tabel 1.

Nilai-nilai $\mu$ ini selanjutnya diperbandingkan dengan nilai $\mu$ hasil simulasi dengan program XCOM yang ditunjukkan dalam tabel 2 .

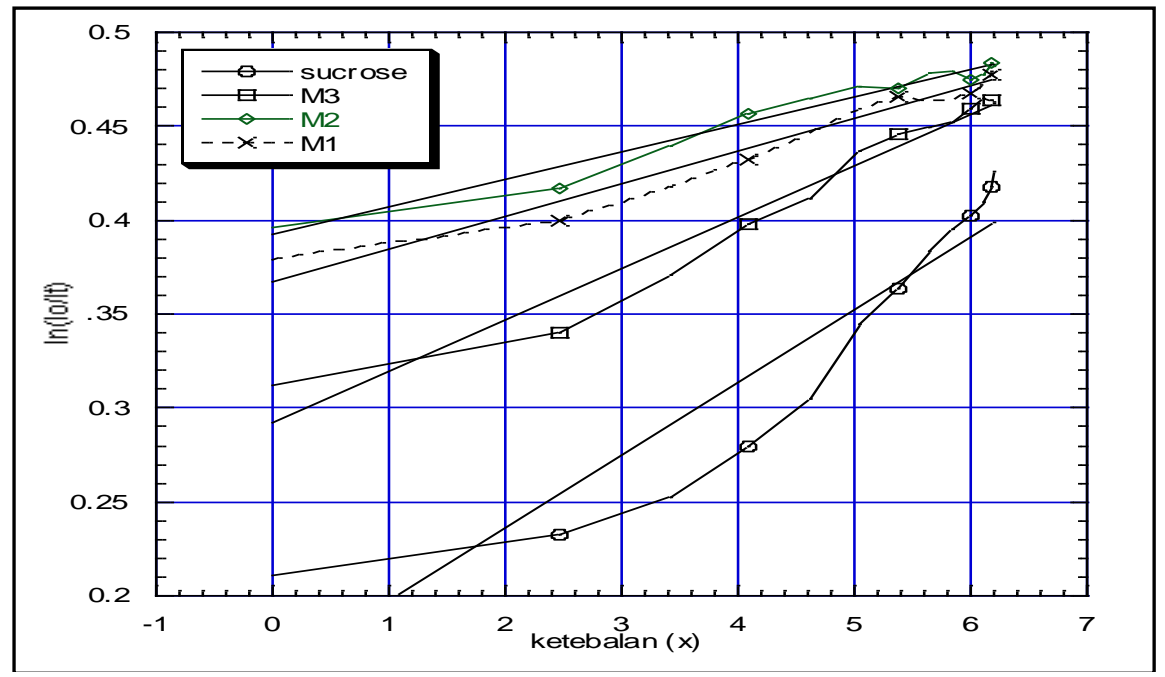

Gambar. 5 Grafik hubungan $\ln \left(\mathrm{I}_{0} / \mathrm{I}_{\mathrm{t}}\right)$ Vs ketebalan pada tegangan $50 \mathrm{Kv}$

Pada tegangan $\mathrm{kV} \quad 50$ dengan menganalisis nilai koefisien serapannya nilai koefisien serapan M3 paling besar diantara nilai koefisien serapan M2 dan M1. Nilai koefisien serapan M1 paling kecil. Jika diurutkan nilai koefisien serapannya dari besar ke kecil adalah 
M3, M1 dan M2. Hal ini juga terjadi pada tegangan $70 \mathrm{kV}$. Pada tegangan $60 \mathrm{kV}$ nilai koefisien serapan M1 lebih besar dibanding M3. Dari simulasi XCOM (Tabel 2), nilai koefisien serapan madu, semakin besar tegangan yang digunakan maka nilai koefisien serapan semakin kecil. Dari data eksperimen, hal ini hanya berlaku untuk tegangan $50 \mathrm{kV}$ dan tegangan $70 \mathrm{kV}$. Pada tegangan $60 \mathrm{kV}$ terjadi penyimpangan. nilai koefisien serapan linier. Dari hasil ini menunjukkan bahwa untuk mengidentifikasi madu lebih baik digunakan pada tegangan 50 dan $70 \mathrm{kV}$. Disamping itu, nilai koefisien serapan pada ketiga madu yang diidentifikasi harusnya memiliki nilai koefisien serapan yang sama, dari data eksperimen hal ini berbeda. Perbedaan nilai koefisien serapan linier pada ketiga madu yang diidentifikasi kemungkinan mengandung komposisi penyusun yang berbeda. Sampel M1 merupakan madu dengan komposisi baik. Dari hasil eksperimen pada tegangan $50 \mathrm{kV}$ dan tegangan $70 \mathrm{kV}$ ditunjukkan bahwa dari kedua sampel uji, nilai koefisien serapan M2 mendekati nilai koefisien serapan M1, sedangkan nilai koefisien serapan M3 sangat jauh berbeda. Hal ini menunjukkan bahwa komposisi penyusun M2 hampir sama dengan M1.

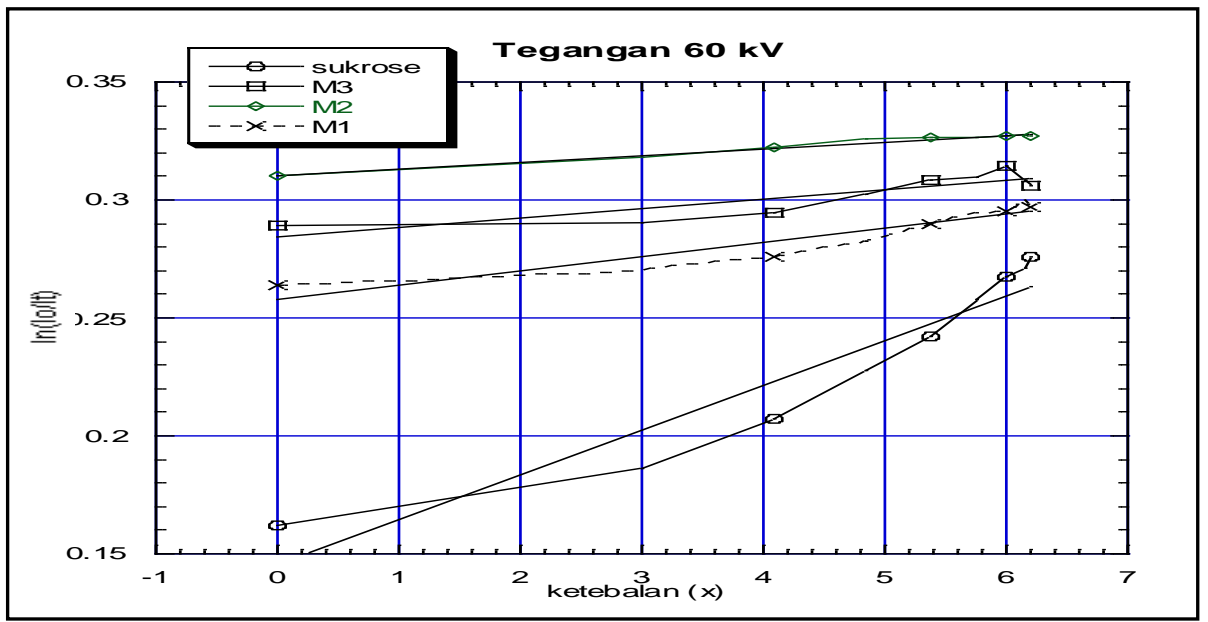

Gambar 6. Grafik hubungan $\ln \left(\mathrm{I}_{\mathrm{o}} / \mathrm{I}_{\mathrm{t}}\right)$ Vs ketebalan pada tegangan $60 \mathrm{kV}$

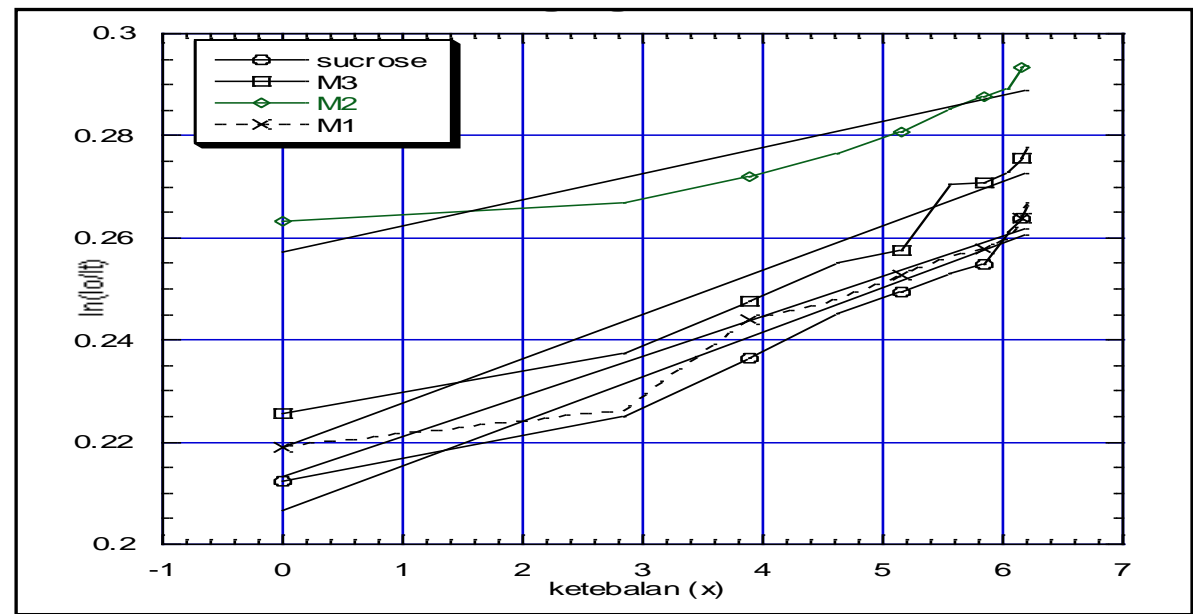

Gambar 7. Grafik hubungan $\ln \left(\mathrm{I}_{\mathrm{o}} / \mathrm{I}_{\mathrm{t}}\right)$ Vs ketebalan pada tegangan $70 \mathrm{kV}$ 
Maiyena, S. 2016. Penggunaan Computed Radiography untuk Identifikasi Madu Lebah. Journal of Sainstek 8(2): 186-192

Tabel. 1. Nilai $\mu$ hasil eksperimen

\begin{tabular}{ccccc}
\hline \multirow{2}{*}{ No } & \multirow{2}{*}{ Sampel } & Tegangann 50 kV & Tegangan 60 kV & Tegangan 70 kV \\
\cline { 2 - 5 } & & $\mu \pm \Delta \mu\left(10^{-3}\right)$ & $\mu \pm \Delta \mu\left(10^{-3}\right)$ & $\mu \pm \Delta \mu\left(10^{-3}\right)$ \\
\hline 1 & Sukrosa & $38.635 \pm 4.506$ & $19.033 \pm 2.324$ & $8.664 \pm 0.392$ \\
2 & M3 & $27.443 \pm 1.703$ & $3.9492 \pm 0.836$ & $8.672 \pm 0.873$ \\
3 & M2 & $14.628 \pm 0.819$ & $2.8229 \pm 0.168$ & $5.0972 \pm 0.756$ \\
4 & M1 & $17.274 \pm 0.387$ & $5.9954 \pm 0.858$ & $7.8037 \pm 0.753$ \\
\hline
\end{tabular}

Tabel. 2. Nilai $\mu$ hasil simulasi XCOM

\begin{tabular}{cccc}
\hline Sampel & Tegangan $50 \mathrm{kV}$ & Tegangan $60 \mathrm{kV}$ & Tegangan $70 \mathrm{kV}$ \\
\hline M1, M2,M3 & 211.0 & 193.7 & 184.15 \\
Sukrosa & 210.2 & 193 & 183.55 \\
\hline
\end{tabular}

Nilai koefisien serapan untuk sukrosa pada ketiga variasi tegangan yang digunakan memberikan hasil bahwa semakin besar tegangan yang diberikan maka nilai koefisien serapan semakin kecil. Hal ini sama halnya dengan nilai koefisien serapan linier berdasarkan simulasi XCOM (Tabel 2). Jadi, dalam hal ini sukrosa bisa digunakan untuk ketiga variasi tegangan $(50 \mathrm{kV}, 60 \mathrm{kV}$ dan 70 $\mathrm{kV})$.

\section{KESIMPULAN}

Pada penggunaan Computed Radiography, ketiga bahan madu dapat dibedakan pada tegangan 50 dan tegangan 70 $\mathrm{kV}$, bahan sukrosa dapat diidentifikasi pada ketiga variasi tegangan $(50 \mathrm{kV}, 60 \mathrm{kV}$ dan 70 $\mathrm{kV})$.

\section{DAFTAR KEPUSTAKAAN}

Adriani R. 2011. Identifikasi Dan Karakterisasi Sifat Kimia dan Sifat Fisika Dari Madu Asli Dengan Madu Yang Dijual Di Pasaran Medan. Skripsi : FMIPA USU.
Bessler F, Bauer W. 2008. X-Ray Net Weight Control of Pharmaceutical Products, $17^{\text {th }}$ World Con ference on Nondestructiv $e$ Testing, Shanghai, China.

Cahyono HA. 2003. Inspeksi Keramik dengan Radiografi Sinar-X, Skripsi S-1, FMIPA UGM, Yogyakarta.

Fidiani E. 2008. Studi Awal Inspeksi Kandungan Logam dalam Cat dengan Teknik Computed Radiography, Skripsi S-1, FMIPA UGM, Yogyakarta.

Maun S. 1999. Pemalsuan Madu Dengan Sakarosa. Jurnal Kedokteran Trisakti. Januari-April 1999-Vol. 18, No. 1.

Pasolang G. 2003. Inspeksi Pipa Berbasis Radiografi Sinar-X Digital, Skripsi S-1, MIPA, UGM, Yogyakarta.

Setiawan SA. 2002. Interpretasi Radiograf Digital pada Industri Pengelasan Pipa, Skipsi S-1, FMIPA UGM, Yogyakarta.

Suranto A. 2007. Buku Terapi Madu. Jakarta: Penebar Swadaya.

Wahyuningsih M. 2009. Perbandingan Kualitas Citra Computed Radiography Dengan Citra Hasil Digitisasi Film RadIograf, Skripsi-S1, FMIPA UGM. 